\title{
THROMBOTIC THROMBOCYTOPENIC PURPURA: A CASE REPORT
}

\author{
SABRINA SHAHRIN ${ }^{1}$, RAKESH PANDAY ${ }^{2}$, MD. NIAZ MOSTOFA ${ }^{3}$, MOUSUMI SANYAL $^{4}$, MD. MOTLABUR $^{2}$ \\ RAHMAN $^{5}$, AKM AMINUL HAQUE ${ }^{6}$
}

\begin{abstract}
:
Thrombotic thrombocytopenic purpura is a multisystemic microvascular disorder that may be caused by an imbalance between unusually large $v W F$ multimers and the cleaving protease ADAM TS $13^{1}$ (A disintegrin and metalloproteinase with a thrombospondin type 13). This disease was first described by Moshococowitz in $1924 .^{2}$ It is clinically characterized by five typical syndromes: thrombocytopenia, microangiopathic hemolytic anaemia, renal impairment, fluctuating neurological abnormalities and fever. It is a rare disease and fatal in 50 to 80 per cent of cases ${ }^{5}$. TTP can be idiopathic or secondary. Here we are describing a case who developed fever, purpuric spot, jaundice, renal impairment and fluctuating neurological features. Initially it seems to us as a case of DIC, but later hematological evaluation reveals it as a case of TTP, as the patient fulfills the pentad criteria. Unfortunately we could not do the serum ADAM TS 13 level because of lack of facility in our country and in abroad it is costly.
\end{abstract}

Received: 04 May 2014

Accepted: 19 December 2014

Case Presentation:We are reporting a case of a 14 year old boy hailing from Gauranadi, Barishal who presented to us with 2 months history of fever. Initially fever was treated as enteric fever for 10 days. After that fever subsided but later he again developed high grade continued fever. At that time he also developed jaundice, which was static in nature. During the course of his admission he developed blood mixed vomiting, which was fresh initially, but became coffee ground later. Simultaneously he developed passage of black stool 4-5 times per day which was soft in consistency with foul smell, sticky. He also developed convulsion, rigidity, tremor.

There was also visual and gustatory hallucination. Patient also noticed development of rashes which were purpuric $\&$ distributed over face and abdomen, the rash were palpable $\&$ associated with central desquamation, there was no itching. These rashes were subsided after giving steroid. Subsequently he became anuric. But became improved after fluid and diuretics therapy.

On physical examination we found the patient was severely anaemic, moderately icteric. There was ulceration in oral cavity involving palate. His abdomen was distended, flankes were full, liver was enlarged about $5 \mathrm{~cm}$ from the right costal margin along the right mid clavicular line, firm in consistency, smooth, non tender with a sharp border, upper border of liver dullness was at right $5^{\text {th }}$ intercostal space. There was no other organomegally and shifting dullness was positive. On nervous system examination we observed that his higher psychic function was intact initially but later he developed a fluctuating level of consciousness. His muscle tone was increased all over the body, so his jerks were not properly evaluated. There was pill rolling movement of both hands and generalized convulsion was seen for several episodes.

Before admission, investigation shows $\mathrm{Hb}-6.0 \mathrm{gm} /$ dl, S.bilirubin-9.3 mg/dl, PT-23.6 S \& after admission Hb- 3.3 gm/dl, ESR- 05 mm, TC-4130/cmm, Platelets$19000 / \mathrm{cmm}$. After giving four bags of transfusion, $\mathrm{Hb}-$ $9.4 \mathrm{gm} / \mathrm{dl}$, ESR-20 mm, TC-3200/cmm, Platelet$37700 / \mathrm{cmm}$. On $5^{\text {th }}$ day reticulocyte- $2.99 \%$. S.bilirubin decreased gradually.USG suggested acute hepatitis. S.ferritin was high. FDP \& D-dimer were increased. Others important investigations are shown in tables.

1. MO (Med. Unit-VII, DMCH)

2. HMO (Med. Unit-VII, DMCH)

3. HMO (Med. Unit-VII, DMCH)

4. HMO (Med. Unit-VII, DMCH)

5. Assistant Professor (Med. Unit-VII, DMCH)

6. Associate Professor (Med. Unit-VII, DMCH)

Address of Correspondence: Dr. Sabrina shahrin, MO (Med. Unit-VII, DMCH)

Bangladesh J Medicine 2015; 26 : 35-39 


\begin{tabular}{|c|c|c|c|c|c|c|}
\hline$\overline{I N V}$ & $1^{S T} D A Y$ & $2^{N D} D A Y$ & $5^{T H} D A Y$ & $34^{T H} D A Y$ & $41^{S T} D A Y$ & $44^{\text {th }} D A Y$ \\
\hline \multirow[t]{8}{*}{$\mathrm{CBC}$} & $\mathrm{Hb}-3.3 \mathrm{gm} / \mathrm{dl}$ & $\mathrm{Hb}-9.4 \mathrm{gm} / \mathrm{dl}$ & $\mathrm{Hb}-9.1 \mathrm{gm} / \mathrm{dl}$ & $\mathrm{Hb}-7 \mathrm{gm} / \mathrm{dl}$ & $\mathrm{Hb}-6 \mathrm{gm} / \mathrm{dl}$ & $\mathrm{Hb}-10 \mathrm{gm} / \mathrm{dl}$ \\
\hline & ESR-05 mm & ESR-20 mm & & ESR-130 mm & HCT- $18.7 \%$ & \\
\hline & MCV-75 fl & $\mathrm{MCV}-82 \mathrm{fl}$ & & & & \\
\hline & $\mathrm{MCH}-25 \mathrm{pg}$ & $\mathrm{MCH}-41.9 \mathrm{Pg}$ & RET-2.6\% & RET-2.99\% & RET-2.32\% & \\
\hline & MCHC-33.3 gm/dl & MCHC-51 gm/dl & & & & \\
\hline & $\mathrm{TC}-4130 / \mathrm{cmm}$ & TC-3200 / cmm & $\mathrm{TC}-5640 / \mathrm{cmm}$ & TC-10000/cmm & $\mathrm{TC}-11510 / \mathrm{cmm}$ & $\mathrm{TC}-11000 / \mathrm{cmm}$ \\
\hline & N-62.5\%. L-32.9\% & N-62.9\% L-32.6\% & & & N-75\% L-18.3\% & \\
\hline & Plat-19000/cmm & Plat-37700/cmm & Plat-22000/cmm & Plat-3.5 lac $/ \mathrm{cmm}$ & Plat-4.23lac $/ \mathrm{cmm}$ & Plat-4.48 lac/cmm \\
\hline PBF & $\begin{array}{l}\text { Microangiopathic } \\
\text { hemolytic anaemia }\end{array}$ & & & $\begin{array}{c}\text { Dimorphic } \\
\text { anaemia }\end{array}$ & $\begin{array}{c}\text { Normochromic } \\
\text { normocytic anaemia }\end{array}$ & \\
\hline
\end{tabular}

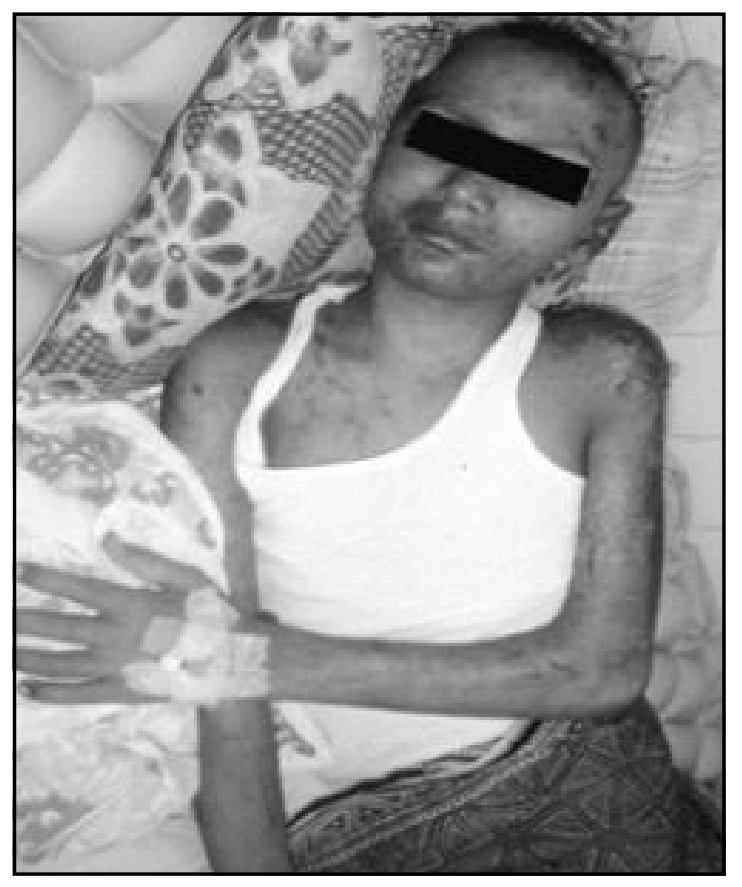

Fig.-1: $P B F$ of $M A H A$

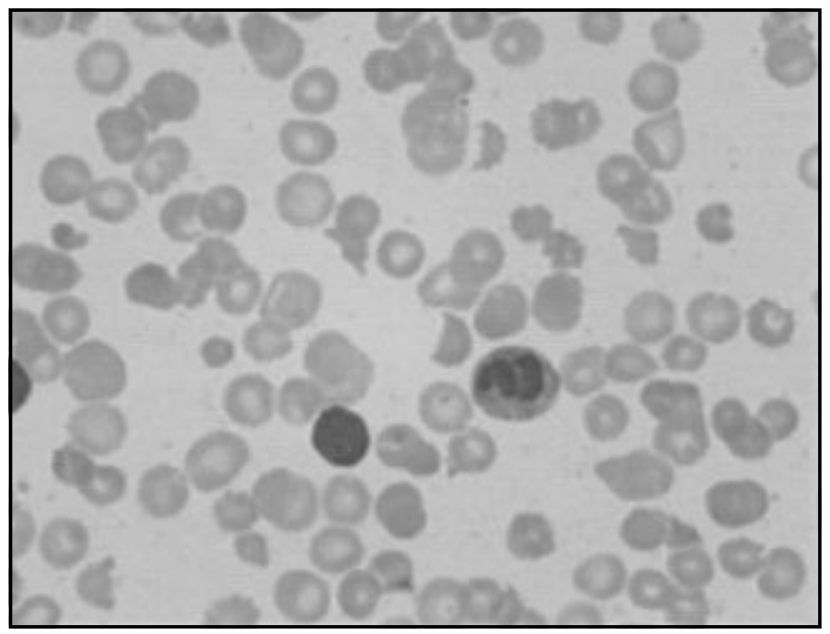

Fig.-2: $P B F$ of $M A H A$

\begin{tabular}{|c|c|c|c|}
\hline INV & $4^{\text {TM }}$ DAY & $14^{\mathrm{TM}} \mathrm{DAY}$ & $45^{\mathrm{TM}} \mathrm{DAY}$ \\
\hline S.Bilirubin & $8.85 \mathrm{mg} / \mathrm{dl}$ & $3.21 \mathrm{mg} / \mathrm{dl}$ & $0.6 \mathrm{mg} / \mathrm{dl}$ \\
\hline$I N V$ & $4^{\mathrm{TM}} D A Y$ & & \\
\hline HBsAg & Negative & & \\
\hline Anti $\mathrm{HBc} \mathrm{Ab}$ & “ & & \\
\hline Anti $\mathrm{HCV}$ & “ & & \\
\hline Anti HAV & “ & & \\
\hline Anti HEV & “ & & \\
\hline Anti Dengu IgM & “ & & \\
\hline ICT for Malaria & “ & & \\
\hline ICT for Kala-azar & $\operatorname{ar}$ & & \\
\hline INV & $5^{\text {th }} \mathrm{DAY}$ & & \\
\hline PT & 125 & & \\
\hline INR & 1.01 & & \\
\hline
\end{tabular}

Coomb's test (direct \& indirect)Negative

\begin{tabular}{lcc}
\hline INV & $6^{\mathrm{TH}} \mathrm{DAY}$ & $14^{\mathrm{TH}} \mathrm{DAY}$ \\
\hline S.Creatinine & $1 \mathrm{mg} / \mathrm{dl}$ & $0.45 \mathrm{mg} / \mathrm{dl}$ \\
S.Urea & $53 \mathrm{mg} / \mathrm{dl}$ & $51 \mathrm{mg} / \mathrm{dl}$ \\
FDP & $15 \mathrm{mcg} / \mathrm{dl}$ & \\
D-dimer & $11.3 \mathrm{ng} / \mathrm{dl}$ & \\
SGPT & $110 \mathrm{U} / 1$ & \\
\hline
\end{tabular}

USG of W/A Suggestive of acute hepatitis Mild to moderate ascities Bilateral renal parenchymal disease 


\begin{tabular}{|c|c|c|c|c|}
\hline INV & $14^{\mathrm{TH}} \mathrm{DAY}$ & $20^{\mathrm{TH}} \mathrm{DAY}$ & $28^{\mathrm{TH}} \mathrm{DAY}$ & $45^{\mathrm{TH}} \mathrm{DAY}$ \\
\hline \multirow[t]{3}{*}{ S. Electrolytes } & $\mathrm{Na}-143 \mathrm{mmol} / 1$ & $\mathrm{Na}-122 \mathrm{mmol} / 1$ & $\mathrm{Na}-129 \mathrm{mmol} / \mathrm{l}$ & $\mathrm{Na}-134 \mathrm{mmol} / 1$ \\
\hline & $\mathrm{K}-2.7 \mathrm{mmol} / 1$ & $4.5 \mathrm{mmol} / 1$ & $\mathrm{~K}-3.8 \mathrm{mmol} / 1$ & $\mathrm{~K}-4.4 \mathrm{mmol} / 1$ \\
\hline & $\mathrm{Cl}-107 \mathrm{mmol} / 1$ & $\mathrm{Cl}-93 \mathrm{mmol} / 1$ & $\mathrm{Cl}-98 \mathrm{~mol} / \mathrm{l}$ & $\mathrm{Cl}-102.26 \mathrm{mmol} / 1$ \\
\hline \multicolumn{2}{|l|}{ S.Ceruloplasmin } & $268.60 \mathrm{ng} / \mathrm{dl}$ & & \\
\hline \multicolumn{2}{|l|}{ 24hrs urine $\mathrm{Cu}$} & $85 \mathrm{mcg} / 1$ & & \\
\hline \multicolumn{3}{|c|}{ Endoscopy of Upper GIT } & \multicolumn{2}{|l|}{ Gastropathy } \\
\hline \multicolumn{2}{|l|}{$\overline{I N V}$} & & $29^{T H} D A Y$ & $40^{T H} D A Y$ \\
\hline \multicolumn{2}{|l|}{$\overline{\mathrm{ANA}}$} & & & \\
\hline \multicolumn{2}{|l|}{$\mathrm{p}-\mathrm{ANCA}$} & & & \\
\hline \multicolumn{2}{|l|}{ c-ANCA } & & & \\
\hline \multicolumn{2}{|l|}{ S.Ferritin } & & $1075 \mathrm{ng} / \mathrm{ml}$ & \\
\hline \multicolumn{2}{|l|}{ S.LDH } & & & $275 \mathrm{U} / \mathrm{L}$ \\
\hline \multirow{4}{*}{ CSF study } & Sugar- 7 & & & \\
\hline & Protein- & & & \\
\hline & Total cell & $\mathrm{mm}$ & & \\
\hline & No AFB/ & ism & & \\
\hline MRI & & & & \\
\hline Blood for $\mathrm{C} / \mathrm{S}$ & No g & & & \\
\hline
\end{tabular}

\section{Discussion:}

Our patient initially presented with bloody diarrhea, jaundice, fever and bleeding from oral mucosa. Typical childhood HUS (hemolytic uremic syndrome) presents with an episode of abdominal pain and bloody diarrhoea that is most often due to shiga toxin producing enterohemorrhagic E. Coli, while TTP usually affect adults. It is acute syndrome associated with thrombi composed of platelets in multiple organ system $^{4}$. The precipitating or causative factors implicated include pregnancy, surgery, antibiotics, OCP, abortions ${ }^{5}$.

Following the discovery that TTP is associated with a severe deficiency of ADAM TS 13 activity, it was suggested that ADAM TS 13 deficiency may become the definitive and diagnostic criterion for TTP ${ }^{3}$. But many patients who fulfill the clinical diagnostic criteria for TTP do not have ADAM TS 13 deficiency ${ }^{3}$.For some authors measurement of ADAM TS 13 activity do not conclusively confirm the diagnosis of TTP, as it may be found decreased in many other acute inflammatory conditions ${ }^{1}$. Our patient fulfills the pentad criteria, so we can say that this is a case of TTP. His clinical features and biochemical markers fully support this.

The three types of thrombotic microangiopathy areTTP, DIC and HUS. The table below will show the differences-

\begin{tabular}{lccc}
\hline & TTP & HUS & DIC \\
\hline Thrombocytopenia & + & + & + \\
Hemolytic anaemia & + & + & $+/-$ \\
Schistocytes & ++ & + & $+/-$ \\
Clinical features & CNS dysfunction, Renal & Diarrhoea, Renal & Features of \\
& impairment, High fever & dysfunction & underlying disease \\
Laboratory findings & ADAM TS 13 decreased & Shiga toxins- & High FDP \\
Treatment & Steroid, PE & Plasma & Treatment of \\
& Immunosuppression & Exchange & underlying \\
& Anti coagulant & & disease \\
\hline
\end{tabular}


From this table it is seen that our patient has all the features of TTP. His FDP and D-dimer levels were raised, but it is reported that this two can be raised in TTP $^{1}$.

There are two types of TTP-congenital and acquired. Congenital TTP (Upshaw-Schulman syndrome) is characterized by the absence or severe deficiency of ADAM TS 13 activity by mutation in the ADAM TS 13 gene. Acquired idiopathic TTP without underlying diseases generally has severe deficiency of ADAM TS 13 activity caused by anti ADAM TS 13 auto antibodies. However acquired TTP due to various underlying diseases often does not show a severe deficiency of ADAMTS 13 activity or the presence of ADAM TS 13 inhibitors. TTP without severe ADAM TS 13 deficiency is termed as thrombotic microangiopathy ${ }^{1}$. For the purpose of distinguishing TTP from TMA (Thrombotic microangiopathy), Fujimora and Matsumoto categorized TTP using plasma level of ADAM TS 13 activity (<3\% severe, $3-25 \%$ moderate, $25-50 \%$ mild) ${ }^{2}$.

The treatment of TTP is quite difficult. Mortality rate was about $90 \%$ before the invention of plasma exchange. Almost 20 years ago plasma exchange was reported to increase survival upto $78 \%$ compared to $51 \%$ survival for patients treated with plasma infusion alone ${ }^{3}$.The British Committee for Standards in Hematology recommends that Plasma exchange therapy continues for a minimum of two days after the return of platelet counts to normal, normalization of neurological status, increased hemoglobin and normalization of $\mathrm{LDH}$. The residual presence of schistocytes in the peripheral blood after normalization of platelet count is common and is not predictive of relapse ${ }^{6}$. Corticosteroids again have a role in acquired TTP for inhibition of the antibodies against ADAM TS 13. Rituximab recommended in the treatment of relapsing or refractory forms of TTP (6). In places like our country where plasma exchange is unavailable, high volume plasma infusion $(30 \mathrm{ml} /$ $\mathrm{kg}$ ) may be given.

We treated our patient with corticosteroid, plasma infusion and supportive measures only. At first we treated him with steroid alone due to diagnostic dilemma. Patients' condition was improved after 10 days. His skin rashes disappeared, fever subsided and renal function was also improved. We started to taper steroid. At that time patient was unable to move his body due to generalized stiffness, for this he developed bed sore. For these ulcers he again developed fever, skin rashes and fluctuating level of consciousness. Now we are treating the patient with plasma infusion and steroids with supportive therapy.

\section{References:}

1. Arimoto $\mathrm{M}$, Kmiyama $\mathrm{Y}$, Okomee $\mathrm{F}$, Ichibe $\mathrm{A}$, Teranishi $\mathrm{S}$, Tokunago $\mathrm{H}$, et all. A case of thrombocytopenic purpura induced by acute pancreatitis Dove press, Date- March 2012, Vol: 2012:5, Page 307-311.

2. Yamada R, Nozawa K, Yoshimine T, Takasaki Y, Ogawa H, Takamori K, et all. A case of Thrombotic Thrombocytopenic Purpura associated with Systemic Lupus Erythematosus: Diagnostic Utility of ADAM TS 13 activity Autoimmune diseases, volume 2011, Article 10-483642 (6 pages)

3. Domian JT, Filho S, de Barros PV, Rios AMY, da Silva P, Barbosa FA, et all.Thrombotic Thrombocytopenic Purpura associated with Mixed Connective Tissue Disease: A Case Report. Case reports in medicine, Vol: 2011, Article ID: 953890 (5 pages)

4. See JRH, Sabagh T, Barde CJ. Thrombotic Thrombocytopenic Purpura: A Case Presenting With Acute Ischemic Colitis. Case reports in Hematology (Hindawi Corporation), Volume: 2013, Article ID: 592930, (4 pages)

5. Parikh PM, Chill VS, Mehta BC, Anjaria PD. Thrombotic Thrombocytopenic Purpura (a case report) Journal of post graduate medicine, Year 1987, Vol: 33, Issue-2, page 105-7.

6. Khayat SSE, Medkouri G, Etomba AM, Zamd M, Gharbi MB, Ramadani B. Thrombotic Thrombocytopenic Purpura and Systemic Lupus Erythematosus: a Rare and Life Threatening Association. Arab journal of Nephrology and Transplantation, Date 2012, May, 5(2):103-5. 